\title{
INVESTIGATION OF RUBBLE-MASONRY WALL CONSTRUCTION PRACTICE IN LATIUM, CENTRAL ITALY
}

\author{
O. ALSHAWA ${ }^{1}$, G. DE CANIO ${ }^{2}$, G. DE FELICE ${ }^{3}$, S. DE SANTIS ${ }^{3}$, S. FORLITI ${ }^{2}$, \\ D. LIBERATORE ${ }^{1, *}$, D. MIRABILE GATTIA ${ }^{4}$, S. PEROBELLI $^{1}$, F. PERSIA $^{4}$, \\ G. ROSELLI ${ }^{5}$ AND L. SORRENTINO ${ }^{1}$ \\ ${ }^{1}$ Department of Structural and Geotechnical Engineering, Sapienza University of Rome \\ Via Antonio Gramsci 53, 00197 Rome, Italy \\ e-mail: \{omar.alshawa, domenico.liberatore, luigi.sorrentino\}@uniroma1.it \\ perobelli.1816032@studenti.uniroma1.it, Web page: www.disg.uniroma1.it \\ ${ }^{2}$ Department for sustainability, Laboratorio Tecnologie per la Dinamica delle Strutture e la \\ Prevenzione del rischio sismico e idrogeologico, ENEA Centro Ricerche Casaccia \\ Via Anguillarese 301, 00123 Santa Maria di Galeria (Rome), Italy \\ Email: \{gerardo.decanio, sara.forliti\}@enea.it \\ Web page: www.enea.it \\ ${ }^{3}$ Department of Engineering, Roma Tre University \\ Via Vito Volterra 62, 00146 Rome, Italy \\ Email: \{gianmarco.defelice, stefano.desantis\}@uniroma3.it \\ Web page: www.romatrestrutture.eu \\ ${ }^{4}$ Department for sustainability, Chemical and physical technologies Laboratory in the Division \\ Sustainable Materials, ENEA Centro Ricerche Casaccia \\ Via Anguillarese 301, 00123 Santa Maria di Galeria (Rome), Italy \\ Email: \{daniele.mirabile, franca.persia\}@enea.it \\ Web page: www.enea.it \\ ${ }^{5}$ School of Architecture and Design, University of Camerino \\ Colle dell'Annunziata, Via della Rimembranza, 63100 Ascoli Piceno, Italy \\ Email: graziella.roselli@unicam.it, Web page: www.unicam.it
}

Keywords: 2016-2017 Central Italy seismic sequence, Amatrice, Masonry wall section, Masonry geometry, Mortar recipe, Finite-discrete elements

Abstract. The 2016-2017 Central Italy seismic sequence severely affected existing unreinforced-masonry constructions in four regions. Those in Latium region proved the most prone to fragmentation because of an unfortunate combination of undressed natural stone units and very low lime content in mortar. Within the framework of a research project funded by the regional government, shake table tests are planned to investigate masonry disintegration as well as possible intervention techniques, as described in a companion paper. All specimens will have natural stone units retrieved from the debris in Collespada, a settlement of the municipality of Accumoli, one of the most affected by the seismic sequence. To push further the representativeness of the specimens with respect to field conditions, wall geometry, masonry 
fabric and mortar recipe are carefully designed. The wall thickness will be approximately equal to $0.5 \mathrm{~m}$, close to average thickness surveyed in the area. Following the survey of several vertical sections of actual masonry walls, the specimens will present unconnected external leaves with a limited nucleus. Based on tests on mortar sampled from collapsed buildings, mortars will be prepared by a part of natural lime every nine parts of sand. Shear tests on sampled mortar delivered apparent cohesion and friction coefficient that are used as preliminary values of a finite-discrete element model, which can account for masonry fragmentation in dynamic non-linear analyses. The numerical model was tested under the envisioned sequence of records, belonging to the Amatrice station and related to the East component, approximately fault normal, of the two main seismic events, 24 August and 30 October, 2016.

\section{INTRODUCTION}

On 24 August 2016 a severe seismic sequence started in Central Italy with a $M_{w} 6.0$ event originated in the municipality of Accumoli (Figure 1). The sequence counted nine events having $M_{w} \geq 5.0$ until 18 January 2017, and a $M_{w} 6.5$ event on 30 October, the largest earthquake in Italy since 1980, and in Central Italy since 1915. The sequence affected four administrative regions: Abruzzi, Latium, Marches, and Umbria, but the most catastrophic collapses occurred in Latium, in the municipalities of Accumoli and Amatrice [1,2]. The response of historical in comparison to other Already the first event (Figure 2), leading disintegration occurs a box-like behaviour go

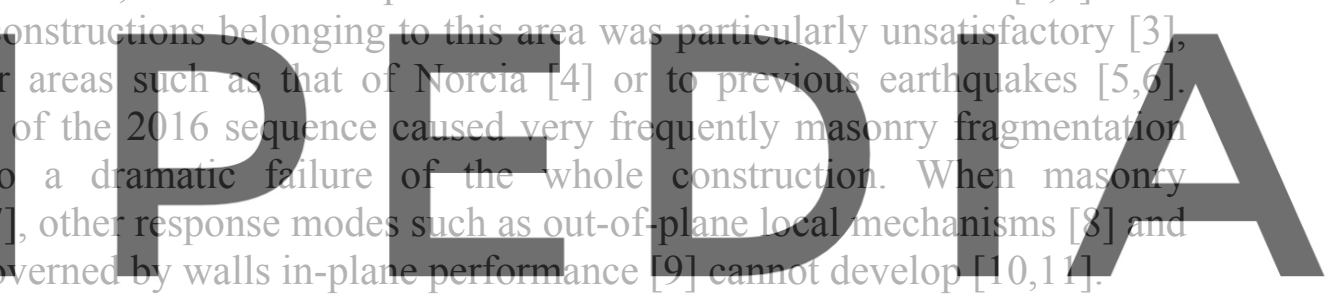

Register for free at https//www.scipedia.com to download the version without the watermark

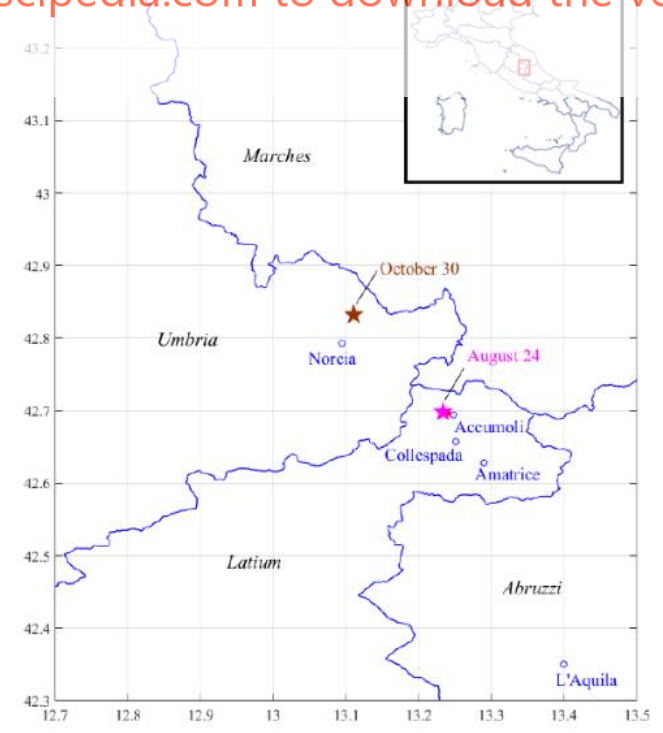

Figure 1: Map of the area affected by the 2016-2017 Central Italy seismic sequence 


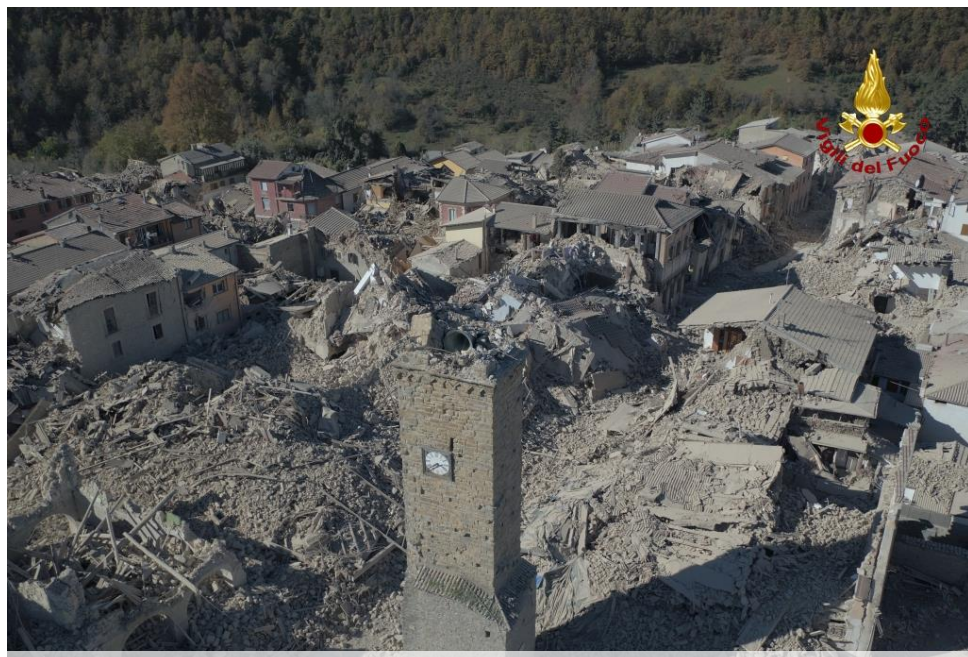

Figure 2: Amatrice historical centre, after the 24 August event in a snapshot from a movie released by the Firefighters Corps (www.vigilfuoco.tv)

Seismic demand in and around Amatrice was certainly severe, but not more than in Norcia [12], highlighting a higher vulnerability of the buildings in the portion of Latium closest to the

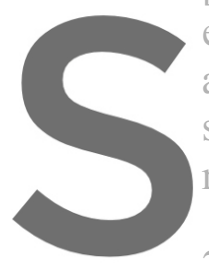
epicentral area. In order to deepen the understanding of this appropriately the characteristics strengthening interventions reported hereinafter.

\section{SURVEY OF MASONRY WALL PRACTICF}
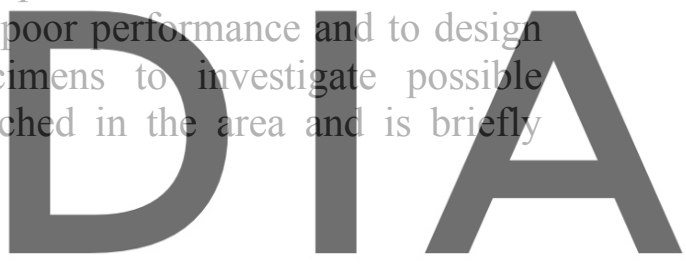

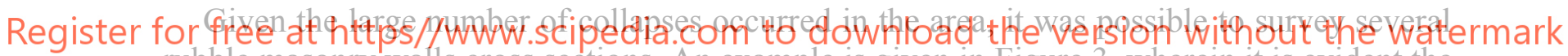
rubble masonry walls cross sections. An example is given in Figure 3, wherein it is evident the lack of bond stones and the presence of a nucleus, largely constituted by small-size units. Additionally, horizontal mortar joints are frequently discontinuous and vertical joints are not properly staggered. Despite the use of compact limestone as unit material, because of the poor mortar's properties described in the following, the overall characteristics of the walls were extremely inadequate, as can be shown computing the masonry quality index proposed by Borri et al. [14] or by comparison with wall sections in L'Aquila [15]. The specimens of the envisioned laboratory investigation [13] will reflect these characteristics.

Additionally, wall geometries have been investigated in terms of ground floor thickness, wall height, transverse wall spacing, building number of stories (Figure 4). Average wall thickness was about $0.6 \mathrm{~m}$ and height/thickness ratio about 11 . These values are smaller and larger, respectively, of those reported for L'Aquila [16], thus contributing to explain the higher vulnerability of the buildings of Accumoli and Amatrice. An approximate thickness of $0.5 \mathrm{~m}$ will be used for the wall specimens to be tested on the shake table [13]. 

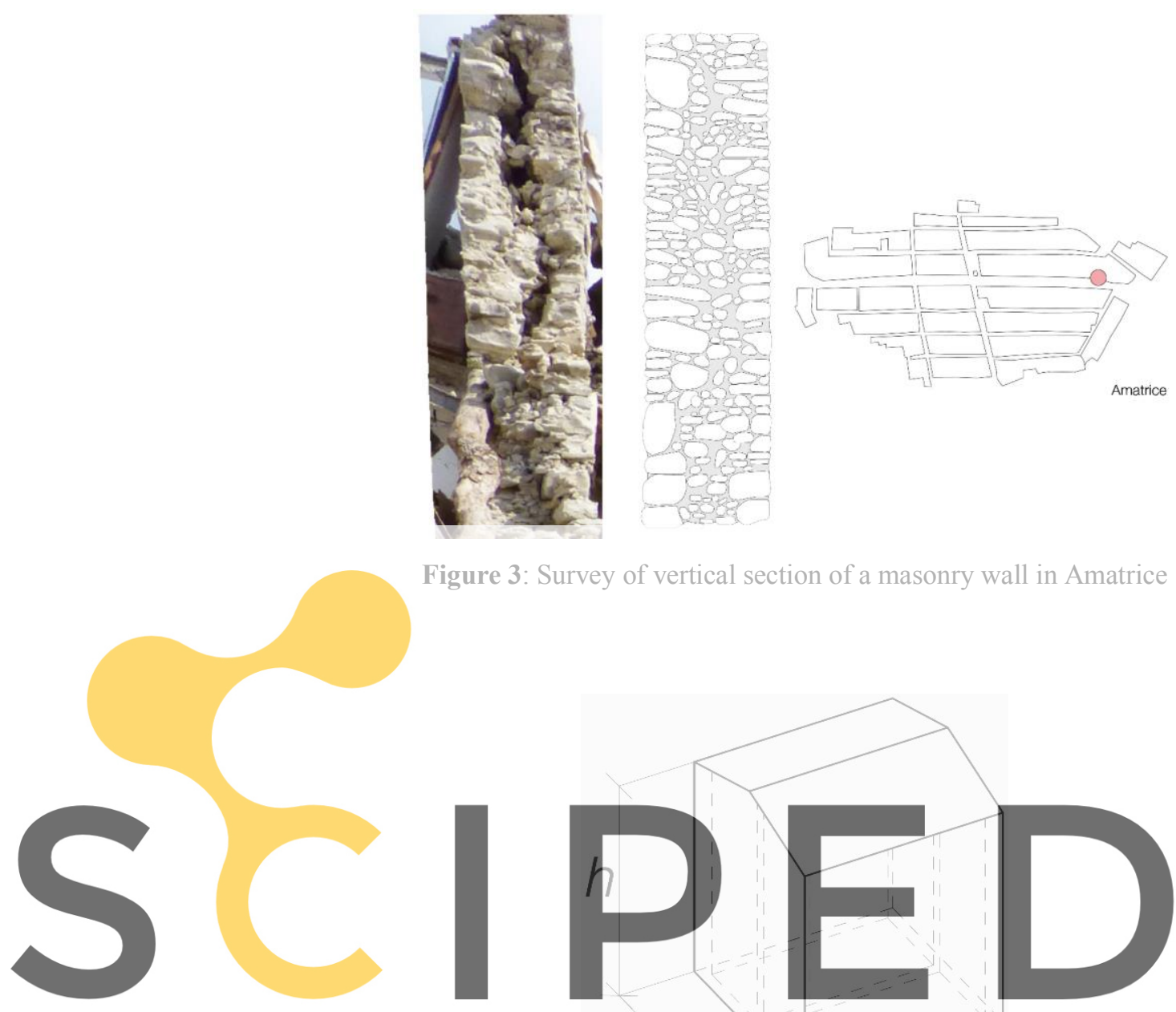

Figure 3: Survey of vertical section of a masonry wall in Amatrice

\section{Register for free at https//www.scipedia.com to download the version without the watermark}

Figure 4: Survey of walls geometry

The walls to be tested will be manufactured with natural stone units retrieved from the debris of the buildings in the settlement of Collespada, within the municipality of Accumoli (Figure 1). However, mortar cannot be retrieved in the same way, and will be manufactured for this laboratory campaign. Therefore, it is necessary to properly design the mortar recipe in order to make it representative of local construction practice. The mortar sampled from buildings severely damaged by the 2016-2017 seismic sequence was investigated within a larger endeavour [17,18], involving also Marches and Umbria regions. On mortar samples, mechanical, physical and chemical experimentations were performed.

Mechanical investigations involved direct shear tests (Figure 5a), performed cyclically for different normal-stress levels. Values for the Latium samples are reported in Table 1, highlighting an average friction coefficient of about 0.9 and cohesion of about $25 \mathrm{kPa}$. These values will be used in the numerical model presented in the following. Cyclic behaviour resulted remarkably stable (Figure 5b). 

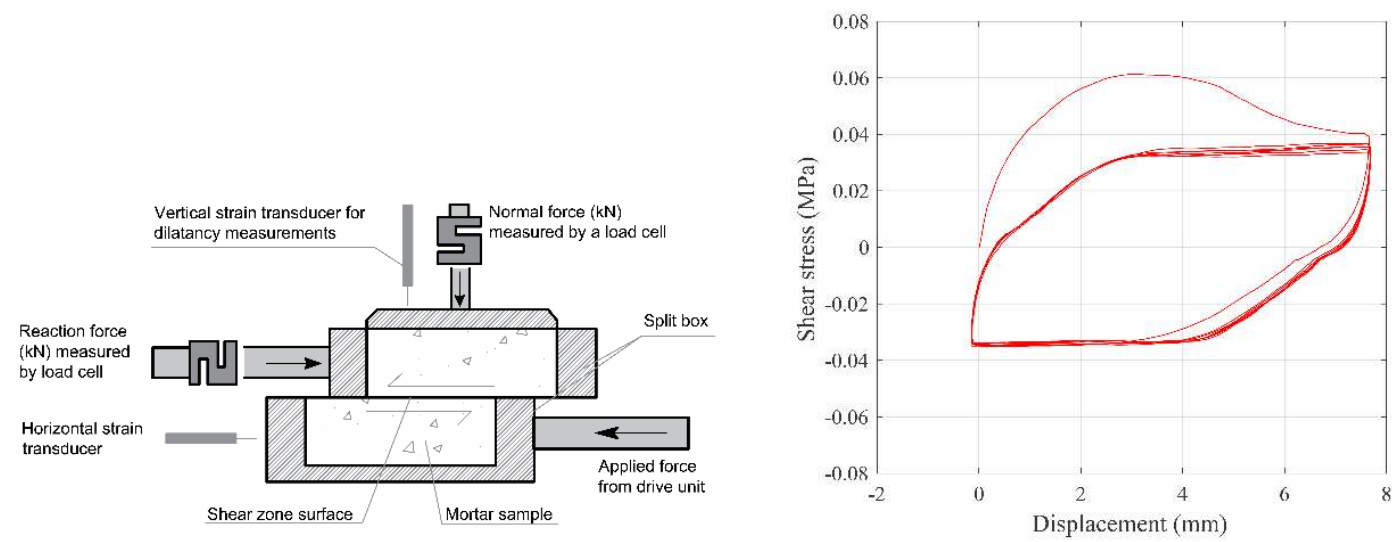

Figure 5: a) Direct shear test, b) Example of shear force vs. displacement curve

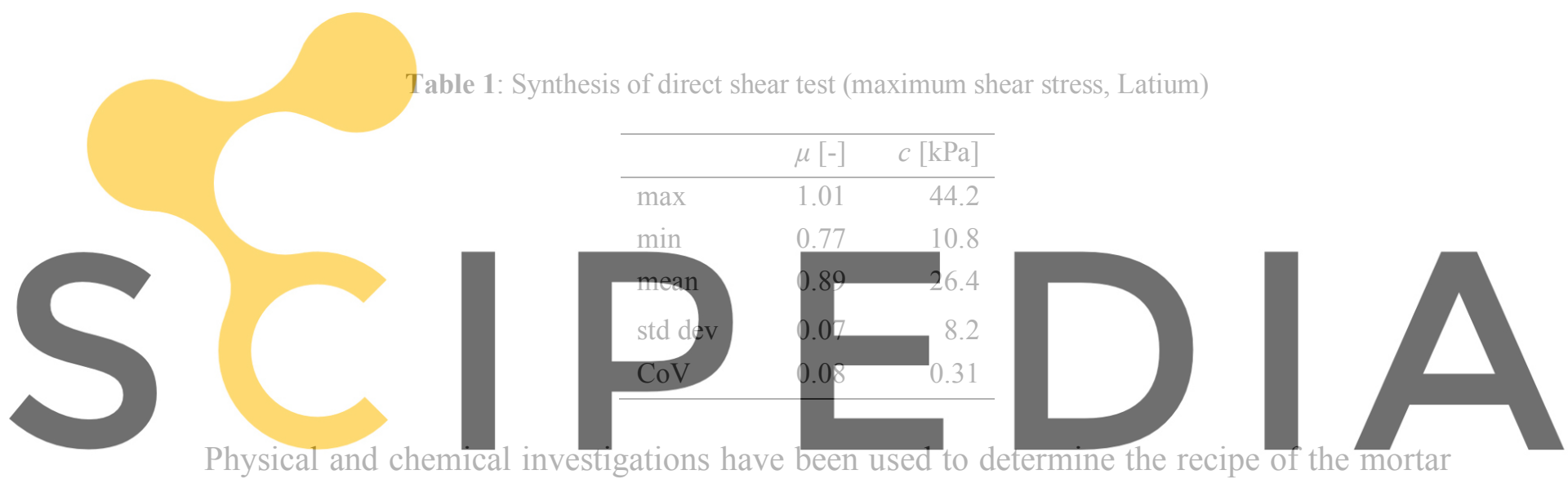

Physical and chemical investigations have been used to determine the recipe of the mortar mix such as infrared spectroscopy, calcimetry and X-ray diffraction. Infrared spectroscopy

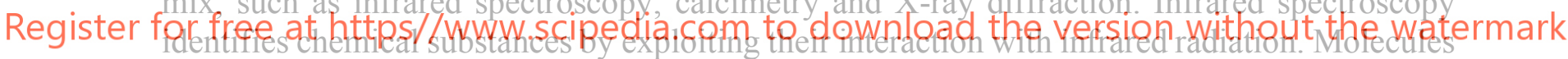
absorb radiations matching their resonant frequencies, thus allowing their detection. A qualitative analysis of the associated Fourier-transform spectra, confirmed by crystaline phase analysis performed by X-Ray diffraction, allows recognising the very large presence of silicates in Latium mortars in comparison with those in the other investigated regions corresponding to a lower content of carbonates (Figure 6a,b).

Since carbonates can be present in mortar both as binder and as aggregate, the identified proportion represents an upper bound for actual lime proportion. Nonetheless, it is interesting to observe that even such an upper bound is very low in Accumoli and Amatrice. This qualitative observation is confirmed by quantitative tests performed with a calcimeter. In this instrument the carbonate is exposed to hydrocloridic acid and the pressure increase related to the released carbon dioxide is measured, hence estimating the mortar carbonate percentage at about $11 \%$ (Figure $6 \mathrm{c}$ ). Such low presence is an indicator of a seismic risk awareness lower than in other areas such as that of Norcia [19]. Based on previous results, a proportion of 1 lime part by 9 sand parts will be intentionally used when manufacturing the unretrofitted and retrofitted walls to be tested on the shake table [13].

Having determined a tentative composition of the mortar, standardised $40 \mathrm{~mm} \times 40 \mathrm{~mm} \times$ 
$160 \mathrm{~mm}$ specimens were manufactured to perform bending (Figure 7) and compression (Figure 8) tests according to EN 1015-11 [20]. As expected, flexural response is rather brittle, while compressive one is remarkably ductile. Average strength values in bending and compression at 28 days are $0.13 \mathrm{MPa}$ and $0.40 \mathrm{MPa}$, respectively. Tests were performed also at a reduced number of days in order to preliminarily investigate the possibility of constructing natural-scale walls with such poor mortars.
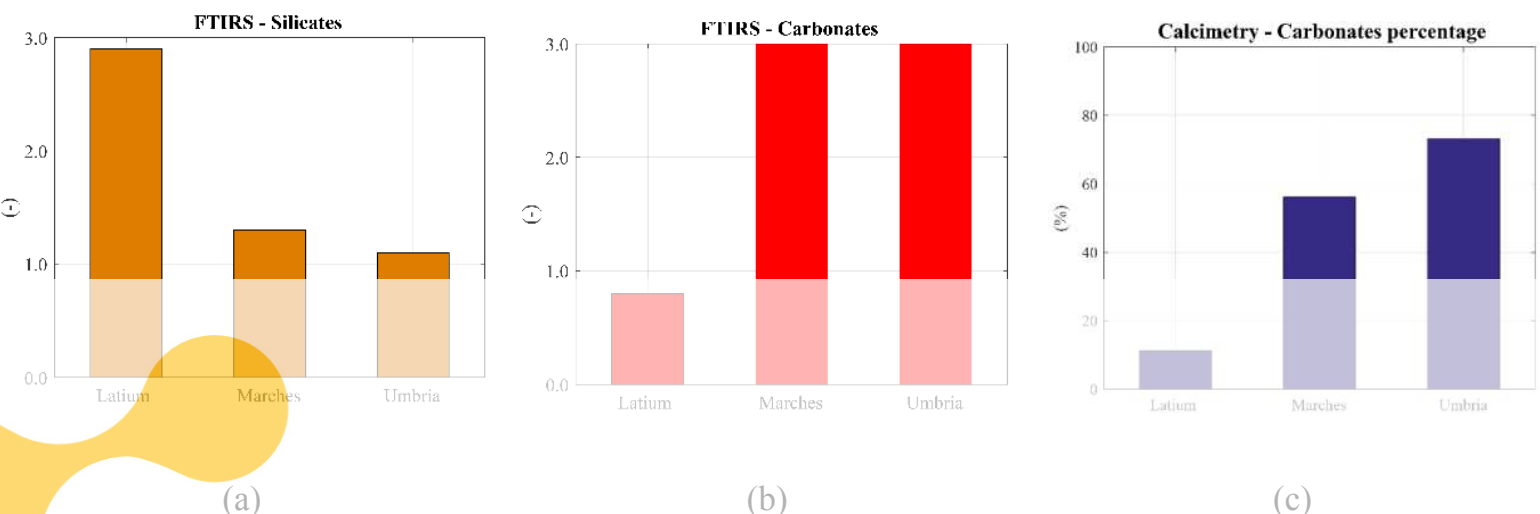

(b)

(c)

Figure 6: Mortar analysis: a) Fourier-transform infrared spectroscopy, silicates; b) Fourier-transform infrared
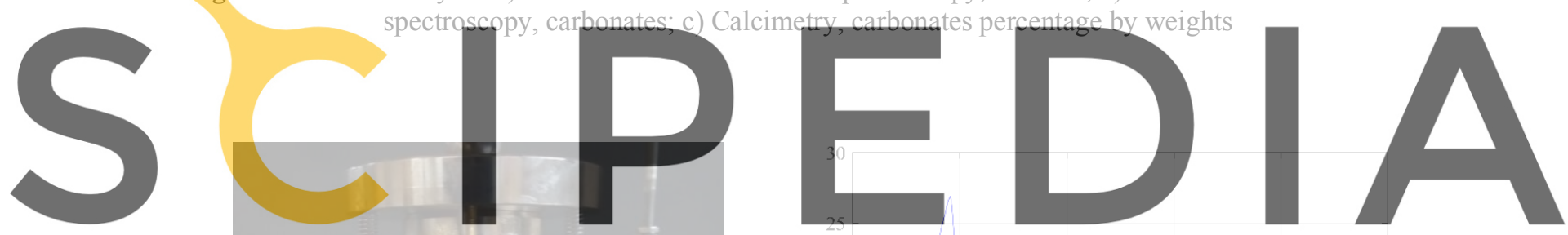

Register for free at https//www.scipedia.com to download the version without the watermark

a)
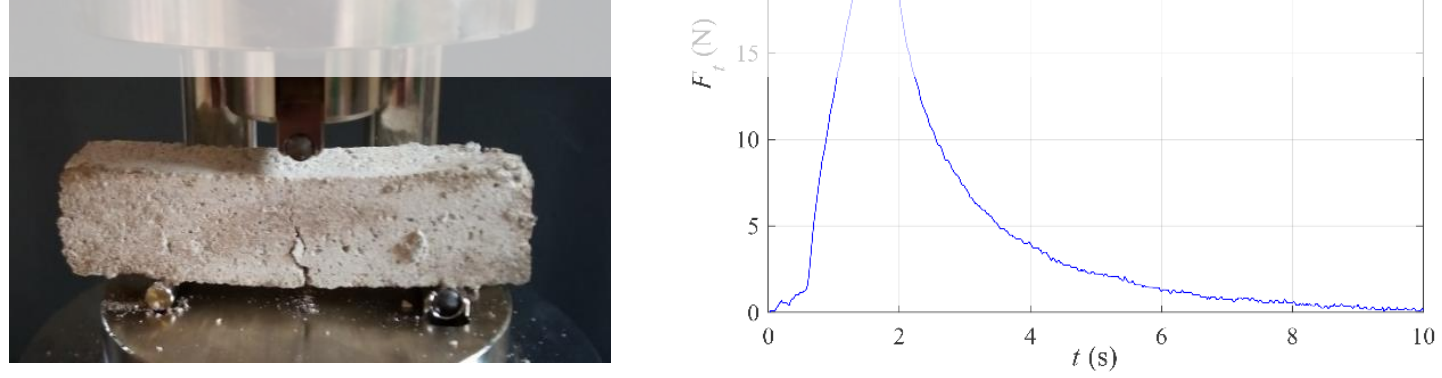

b)

Figure 7: a) Bending test on mortar prism, b) Force time history 
a)
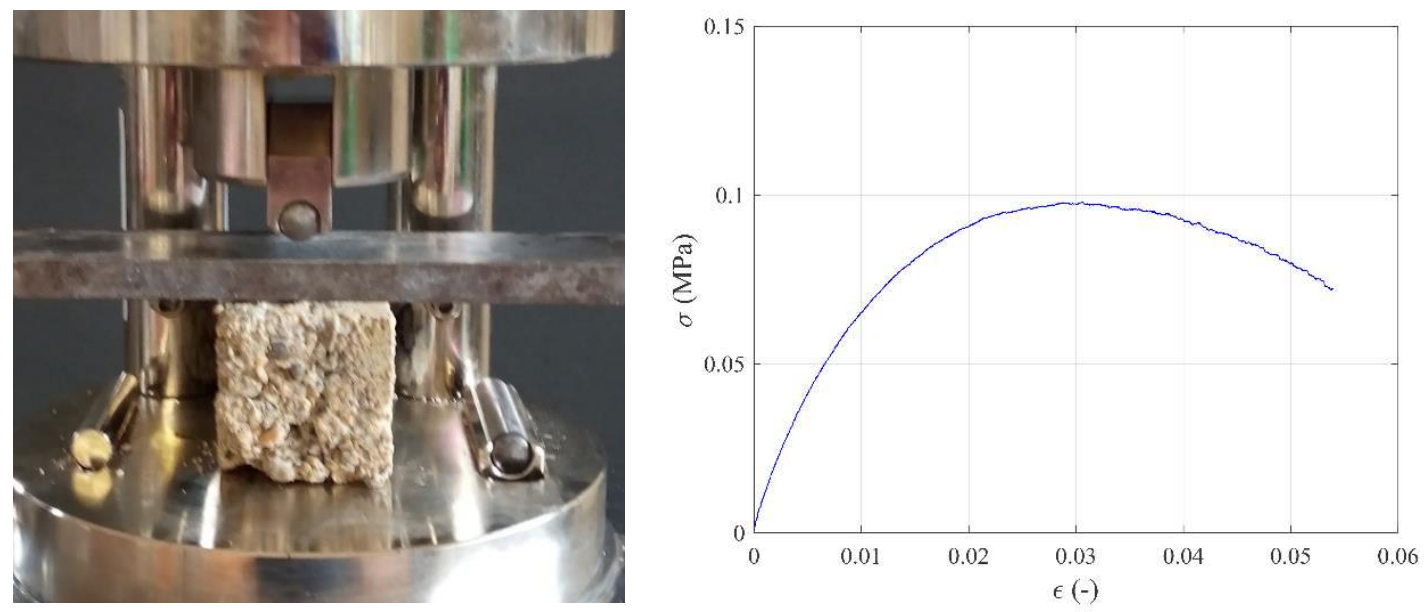

b)

Figure 8: a) Compression test on mortar, b) Stress-deformation plot

\section{NATURAL ACCELEROGRAMS SELECTION FOR THE SHAKE TABLE TESTS}

Shake table tests will investigate the propensity of masonry to fragmentation and possible strengthening techniques. Walls will have a natural scale and will be loaded along the out-ofplane direction. The walls will rest on a reinforced-concrete foundation and horizontal

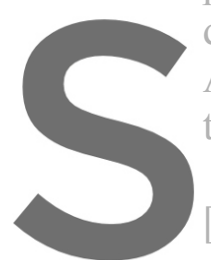
displacement at the top

Additional information

the appropriate accelero

The model was implemented in LS-DYNA

[22]. The wall was nodelled within a combin

elsewhere [23], in order to represent the actual ming
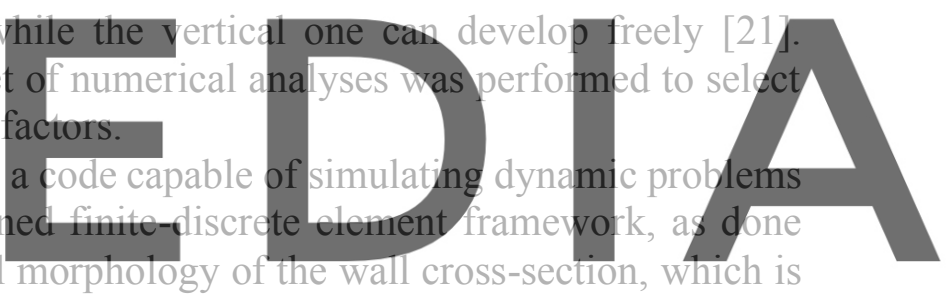

a crucial element in case of out-of-plane seismic loads [24]. The model accounts for the elastic

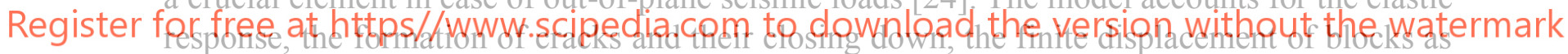

well as the formation of new contacts. All materials are linear elastic, the interfaces between

biocks initiaily in contact react to both compressive and tensile forces, and a standard penaity method governs the contact behaviour through linear springs. Springs fail in tension when the normal stress on the contact surface is greater than the normal failure limit stress. Similarly, springs fail in shear when the shear stress is greater than the shear failure limit stress. After that, a frictional sliding is possible and is governed by static and dynamic friction coefficients.

The physical walls will have two external leaves and a central nucleus made of smaller units. Such arrangement is reproduced in the numerical wall, although with a simplified geometry (Figure 9a). Contact parameters have been preliminarily calibrated based on previously described mortar tests. Given that the experimental program was motivated by the 2016-2017 seismic sequence, the numerical model was tested using the records of the Amatrice station, already in place at the time of the first event. The East component, approximately fault normal and more severe, was selected and the two main events of the sequence, 24 August and 30 October, were chosen as representative of possible damage accumulation [12]. However, in order to study the incremental response of each wall, the amplitude of the records, both horizontal and vertical, will be scaled according to a non-dimensional factor $S_{f}$ increased by 
0.25 steps. In Figure 10 it is possible to observe the sequence of records preceded by the initial slow application of gravity, necessary to avoid unrealistic vibrations. The response and the damage accumulation can be monitored by means of the variation of the distance between the two external leaves at a specific height (Figure 9a). The corresponding time history is given in Figure 11, and it highlights that failure (Figure 9b) occurs for $S_{f}=0.50$ of the 30 October 2016 event.

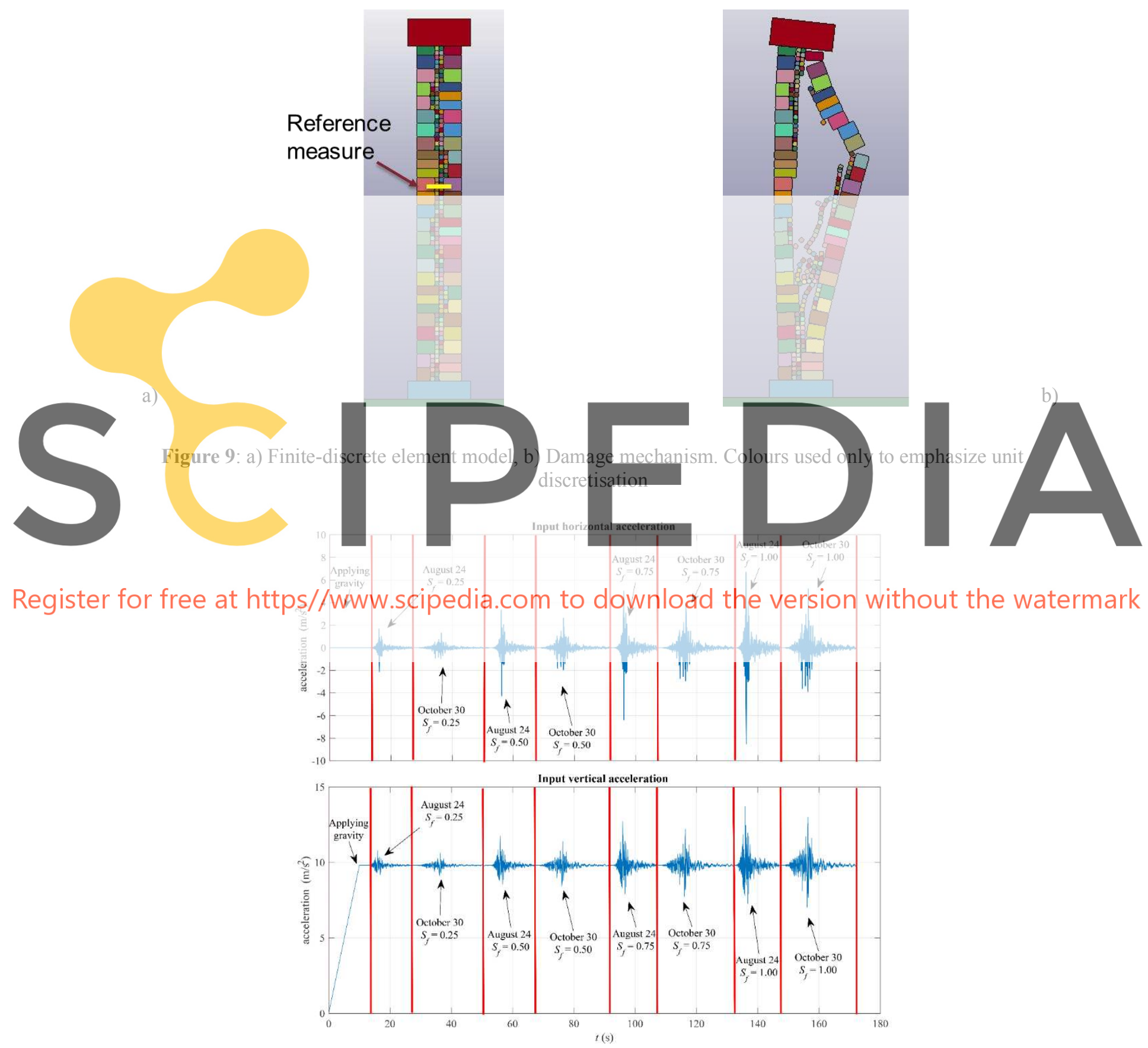

Figure 10: Input horizontal and vertical acceleration time histories (time lapse between two events $2 \mathrm{~s}$ ) 


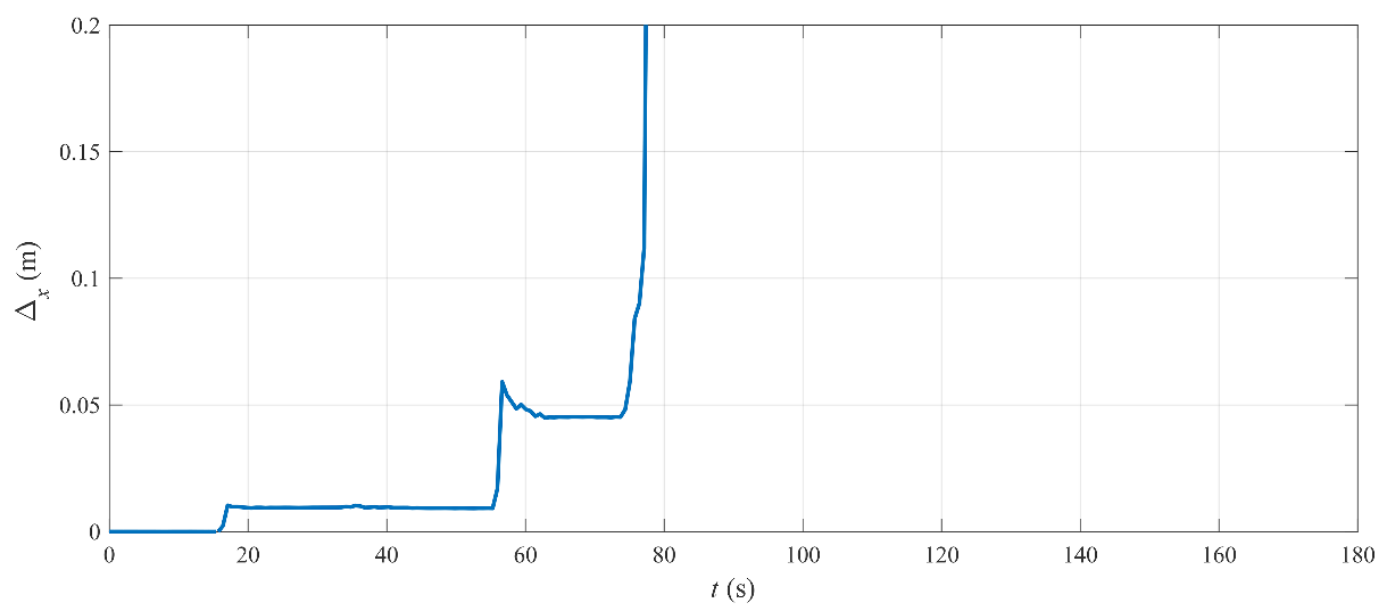

Figure 11: Variation of the distance between the external leaves (Figure 9a) time history

\section{CONCLUSIONS}

The 2016-2017 Central Italy seismic sequence has determined a dramatic performance in historical masonry constructions in the portion of Latium region affected by severe ground shaking. To contribute explaining this behaviour, construction practice was investigated.

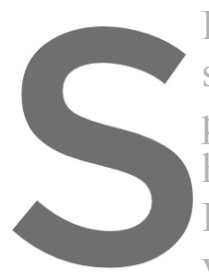
Rubble masonry walls sect small-size and undresse poorer quality compare height/thickness ratio L'Aquila. Infrared spectroscopy, calcimetry very low lime percentag
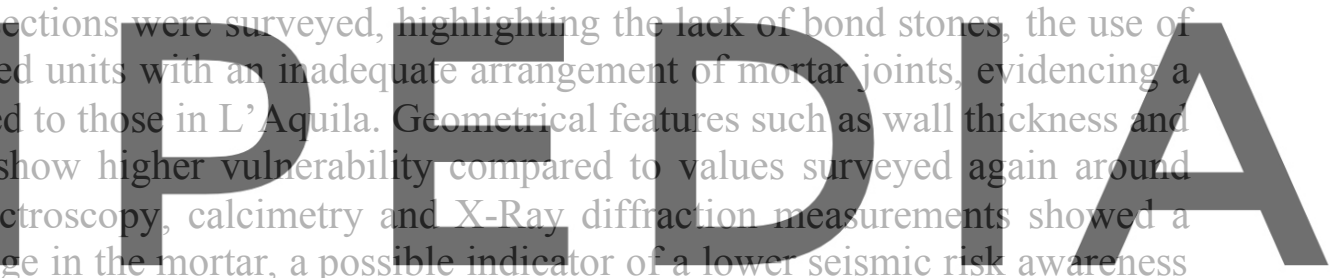
compared to Norcia.

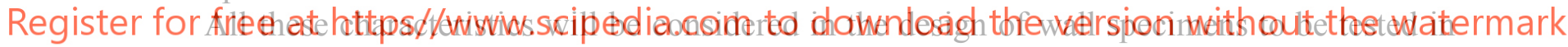
unstrengthened and strengthened conditions on a shake table. Moreover, in order to select the proper sequence of records to be used as excitation, a finite-discrete element model was implemented. The model is tested with a sequence of accelerograms obtained by scaling those recorded in the Amatrice station during the two main events of the seismic sequence, accounting for both the east-west and up-down components. The tentative scale factor adopted will allow for about four tests before the unstrengthened wall reaches failure.

Acknowledgements. This work was partially carried out within the Research Project "SISMI Technologies for the improvement of the seismic safety and the restoration of historical centres" (2018-2020) funded by Latium Region. GdF and SDS acknowledge funding also by Lazio Region within the Research Project "SICURA Sustainable technologies for the seismic protection of the cultural heritage" (2018-2020) and by the Italian Ministry of Education, University and Research (MIUR), attributed to the Department of Engineering of Roma Tre University, within the framework of the Departments of Excellence Initiative (2018-2022). 


\section{REFERENCES}

[1] Azzaro, R., Tertulliani, A., Bernardini, F., Camassi, R., Del Mese, S., Ercolani, E., Graziani, L., Locati, M., Maramai, A., Pessina, V., Rossi, A., Rovida, A., Albini, P., Arcoraci, L., Berardi, M., Bignami, C., Brizuela, B., Castellano, C., Castelli, V., D’Amico, S., D’Amico, V., Fodarella, A., Leschiutta, I., Piscini, A., Sbarra, M., The 24 august 2016 Amatrice earthquake: Macroseismic survey in the damage area and EMS intensity assessment. Ann Geophys (2016), 59, 1-10.

[2] Tertulliani, A., Azzaro, R., QUEST - Rilievo Macrosismico per i Terremoti Nell'Italia Centrale. Aggiornamento Dopo Le Scosse Del 26 e 30 Ottobre 2016. Roma (2016).

[3] Fiorentino, G., Forte, A., Pagano, E., Sabetta, F., Baggio, C., Lavorato, D., Nuti, C., Santini, S., Damage patterns in the town of Amatrice after August 24th 2016 Central Italy earthquakes. Bull Earthq Eng (2018), 16, 1399-1423.

[4] Sisti, R., Di Ludovico, M., Borri, A., Prota, A., Damage assessment and the effectiveness of prevention: the response of ordinary unreinforced masonry buildings in Norcia during the Central Italy 2016-2017 seismic sequence. Bull Earthq Eng (2019), 17, 5609-5629. Penna, A., Morandi, P., Rota, M., Manzini, C. F., da Porto, F., Magenes, G., Performance of masonry buildings during the Emilia 2012 earthquake. Bull Earthq Eng (2014), 12, $2255-2273$

[6] Augenti, N., Parisi, F., Learning from Construction Failures due to the 2009 L'Aquila, Italy, Earthquake. J Perform Constr Facil (2010), 24, 536-555.

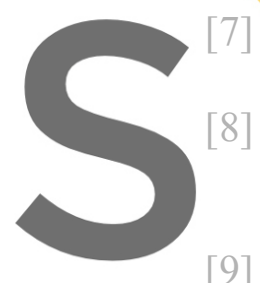
De Felice, G., Out-of-plane seismic cdpal
morphology. Int J Archit Herit (2011),
Doherty, K., Griffith, M. C., Lam, N., W
for out-of-plane bending of unreinforced
31,833-850.
Lourenco, P. B. Mendes, N., Ramos,
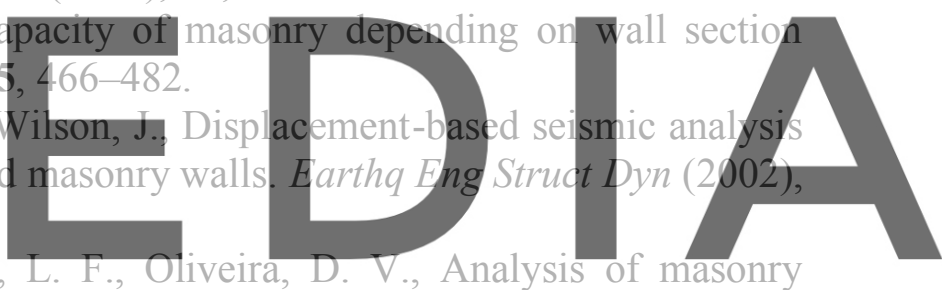
structures without box behavior. Int J Archit Herit (2011), 5, 36.9-382

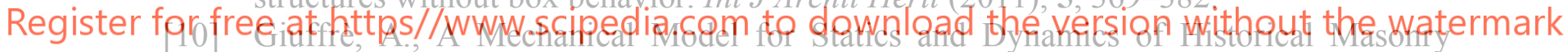

\section{Buildings. Springer, Wien (1996).}

[11] de Felice, G., De Santis, S., Lourenço, P. B., Miendes, N., Miethods and Chalienges for the Seismic Assessment of Historic Masonry Structures. Int J Archit Herit (2017), 11, $143-160$.

[12] Mollaioli, F., AlShawa, O., Liberatore, L., Liberatore, D., Sorrentino, L., Seismic demand of the 2016-2017 Central Italy Earthquakes. Bull Earthq Eng (2019), 17, 53995427.

[13] De Santis, S., AlShawa, O., De Canio, G., Forliti, S., Liberatore, D., Meriggi, P., Roselli, I., Sorrentino, L., de Felice, G., Design of Shake Table Tests of Multi-Leaf Masonry Walls before and after Retrofitting. 12th International Conference on Structural Analysis of Historical Constructions. (2020).

[14] Borri, A., Corradi, M., Castori, G., De Maria, A., A method for the analysis and classification of historic masonry. Bull Earthq Eng (2015), 13, 2647-2665.

[15] Rovero, L., Alecci, V., Mechelli, J., Tonietti, U., De Stefano, M., Masonry walls with irregular texture of L'Aquila (Italy) seismic area: validation of a method for the evaluation of masonry quality. Mater Struct Constr (2016), 49, 2297-2314. 
[16] Sorrentino, L., Reconstruction Plans After the 2009 L'Aquila Earthquake. From Building Performance to Historical Centre Performance. 9th International Conference on Structural Analysis of Historical Constructions, Mexico City, 14-17 October. (2014).

[17] Roselli, G., Mirabile Gattia, D., AlShawa, O., Cinaglia, P., Di Girolami, G., Francola, C., Persia, F., Petrucci, E., Piloni, R., Scognamiglio, F., Sorrentino, L., Zamponi, S., Liberatore, D., Mortar analysis of historic buildings damaged by recent earthquakes in Italy. Eur Phys J Plus (2019), 134, 540.

[18] Mirabile Gattia, D., Roselli, G., Alshawa, O., Cinaglia, P., Di Girolami, G., Francola, C., Persia, F., Petrucci, E., Piloni, R., Scognamiglio, F., Sorrentino, L., Zamponi, S., Liberatore, D., Characterization of historical masonry mortar from sites damaged during the central italy 2016-2017 seismic sequence: the case study of arquata del tronto. Ann Geophys (2019), 62, SE341.1-11.

[19] Marotta, A., Liberatore, D., Sorrentino, L., Historical Building Codes issued after the strong Italian earthquakes of Norcia (1859) and Ischia (1883). Ann Geophys Geophys (2019), 62, SE337.1-13.

[20] EN 1015-11, Methods of Test for Mortar for Masonry. Part 11: Determination of Flexural and Compressive Strength of Hardened Mortar. European Committee for Standardization, Brussels (2006).

[21] De Santis, S., De Canio, G., de Felice, G., Meriggi, P., Roselli, I., Out-of-plane seismic retrofitting of masonry walls with Textile Reinforced Mortar composites. Bull Earthq Eng (2019), 17, 6265-6300.

[22] Hallquist, J., LS-DYNA Theory Manual. Livermore Software Technology Corporation, Livermore (2006).

[23] AlShawa, O., Sorrentino, L., Liberatore, D., Simulation Of Shake Table Tests on Outof-Plane Masonry Buildings. Part (II): Combined Finite-Discrete Elements. Int J Archit Herit (2017), 11, 79-93.

[24] Meriggi, P., de Felice, G., De Santis, S., Gobbin, F., Mordanova, A., Pantò, B., Distinct Element Modelling of Masonry Walls under Out-Of-Plane Seismic Loading. Int J Archit Herit (2019), 13, 1110-1123. 